\title{
AC CONDUCTIVITY AND THERMAL STUDIES OF PAN-NaF DOPED GEL POLYMER ELECTROLYTES FOR SOLID STATE BATTERY APPLICATIONS
}

\author{
Narasimharao Maragani ${ }^{1, *}$, K. VijayaKumar ${ }^{2}$ and N. KrishnaJyothi ${ }^{3}$ \\ ${ }^{1}$ Solid State Ionics Research Laboratory, Dept. of Physics, K. L. University, \\ Guntur-522 502, A.P, INDIA. \\ ${ }^{2}$ Dept. of Physics, Dayananda Sagar Academy of Technology and Management, \\ Bangalore-560 082-INDIA \\ ${ }^{3}$ Department of Physics, K L University, Green Fields, Vaddeswaram, A.P. 522502, India \\ *E-mail: narsigoud@gmail.com
}

\begin{abstract}
Thin film membranes of poly acrylonitrile (PAN) doped with sodium Fluoride (NaF) was prepared by solution casting technique. The Gel polymer Electrolyte films exhibiting an average thickness of $142 \mu \mathrm{m}$. The films were prepared with different (wt \%) ratios. The structural formations were analyzed by X-Ray Diffraction method (XRD).The Conductivity Studies (AC) and thermal conductivity studies (DSC) of the different ratios of gel polymer electrolyte composites were studied. The AC conductivity studies were determined from the impedance data and thermal conductivity studies were measured using the transient electric pulse method. The AC Conductivity increases with increasing temperature and $\mathrm{NaF}$ Concentration. The formed fluoride complexes also contribute in increasing the AC quantities. The DSC measurements showed a decrease in the degree of crystallinity and increase of amorphous regions with increasing concentration of salt $\mathrm{NaF}$. The sample containing 70PAN:30NaF exhibited the maximum conductivity of $1.82 \times 10^{-4} \mathrm{~S} \mathrm{~cm}^{-1}$ at room temperature $(303 \mathrm{~K})$ and $2.96 \times 10^{-3} \mathrm{~S} \mathrm{~cm}^{-1}$ at $373 \mathrm{~K}$.

Keywords: Polymer Gel electrolyte Composite, AC Conductivity Studies, Impedance data, Thermal conductivity.

(C) RASĀYAN. All rights reserved
\end{abstract}

\section{INTRODUCTION}

The development of polymer systems with high ionic conductivity is one of the main objectives in polymer research. This is because of their potential applications as electrolytes in solid-state batteries, fuel cells, electrochemical display devices/smart windows, photo- electrochemical cells etc. ${ }^{1-3}$ The dissolution of low lattice energy salts into a solvating polymer leads to the formation of polymer electrolyte. These can conduct ions and the mobility of these ions can be improved by the addition of plasticizers ${ }^{4}$. Recent research indicates that much effort is being envisaged in developing new energy storing devices in view of day by day increasing in demand for power but depletion in naturally existing resources to meet required demand in this aspect Energy storage devices are assuming importance. ${ }^{5}$ Ion Conducting Gel polymers are considered good candidates to replace traditional metals in specific applications. Indeed, this new generation combines advantages of polymers (lighter weight, mechanical flexibility, easy-processing, biocompatibility, chemical stability) and conducting materials (electrical properties) ${ }^{6}$.Polymer electrolytes find numerous applications in everyday usage as electrochemical devices such as polymer batteries, super capacitors, sensors and electro chromic windows. ${ }^{7}$ The gel polymer electrolytes have been reported with sufficient mechanical strength, high ionic conductivity at room temperature, stable and well compatibility with lithium electrodes. ${ }^{8}$ Due to the unique soft matter characteristics, Gel Polymer Electrolytes (GPEs) have been extensively investigated in the past decades. The GPEs, however, suffer from a trade-off issue between mechanical properties and ionic conductivity. Poly acrylonitrile (PAN) has ionic conductivity and mechanical strength greater than solid polymer electrolyte poly ethylene oxide based electrolytes ${ }^{9,10}$. The development of proton rechargeable batteries would be an interesting study as sodium may be 
considered as an alternative to lithium as negative electrode (anode) due to its low cost, natural abundance, non-toxicity, low atomic mass (23.0) and high electrochemical reduction potential ${ }^{11}$.Many researchers have worked on the conductivity of gel polymer electrolyte systems formed by adding lithium salts to PAN. ${ }^{12-14}$ The Gel Polymeric Electrolytes have a unique hybrid structure, which possesses cohesive properties of solids and diffusive properties of liquids simultaneously ${ }^{15}$.Ethylene carbonate (EC) is a familiar candidate for plasticizer in the gel polymer electrolytes because of its high dielectric constant (95.3) and other attractive properties ${ }^{16}$. The effect of plasticizer in the polymer electrolyte system is to decrease the glass transition temperature and making the polymer become more amorphous and then allowing the ionic carriers to travel freely inside the electrolyte consequently as to raise the ionic conductivity of the electrolyte. ${ }^{17}$ The Gel Polymer Electrolyte Composites were exhibiting sufficient mechanical strength, high ionic conductivity at room temperature, stable and well compatibility with lithium electrodes. ${ }^{18,19}$

The present Paper reports that the effect of dopant concentration on the conductivity Studies (Alternating Current) and thermal Conductivity Studies (DSC) have been investigated to optimize plasticizer concentration providing maximal conductivity and congenial mechanical stability were carried out on PAN based polymer electrolytes.

\section{Materials and Methods}

\section{EXPERIMENTAL}

Poly acrylonitrile (PAN), with average molecular weight 1,50,000 g/mol purchased from Aldrich, Sodium Fluoride $(\mathrm{NaF})$, ethylene carbonate $(\mathrm{EC})$ and dimethyl formamide (DMF) received from Merck, were used as the raw materials in this investigation. All chemicals were used as received without further purification. Appropriate quantities of PAN and $\mathrm{NaF}$ in plasticizing solvents (EC+DMF) are stirred continuously for nearly 36 hours at $50^{\circ} \mathrm{C}$ until a homogeneous solution has been obtained. The homogeneous viscous gel solution was then casted on Petri dishes and dried at $50^{\circ} \mathrm{C}$ for one week. The Fig.-1 represents Prepared Thin film membranes of thickness ranging from 100-150 $\mu \mathrm{m}$ have been obtained.

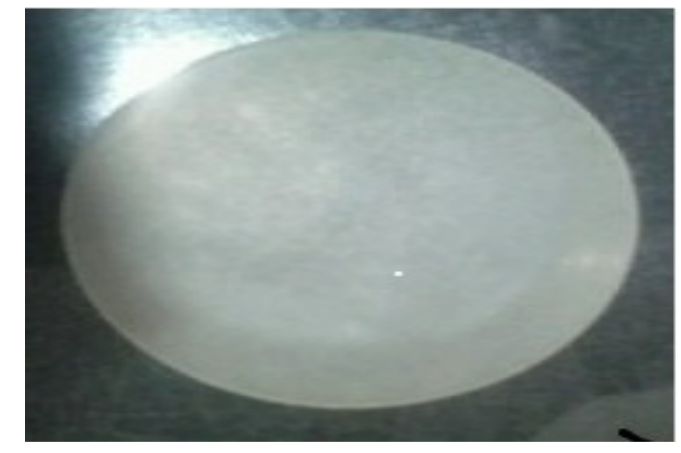

Fig.-1: PAN Complexed Gel polymer Electrolyte film with NaF salt

The prepared films were characterized by using the conductivity values were analyzed in the temperature range from 303-373 K. The A.C conductivity Studies have been measured using the conductivity set up at the room temperature range $303 \mathrm{~K}$ by using HIOKI 3532-50 LCR HITESTER over a frequency range $42 \mathrm{~Hz}-5 \mathrm{MHz}$. The Thermal Conductivity Studies (DSC) were recorded to measure glass transition temperature $\left(\mathrm{T}_{\mathrm{g}}\right)$ and melting temperature $\left(\mathrm{T}_{\mathrm{m}}\right)$ of PAN-based electrolytes by using Mettler-Toledo DSC $822 \mathrm{e}$ with a heating rate of $10^{\circ} \mathrm{C} / \mathrm{min}$.

\section{XRD Studies}

\section{RESULTS AND DISCUSSION}

Generally polymer electrolytes were composed of amorphous nature and crystalline nature. XRD technique is widely used to study the phase compositions of polymer electrolytes. Inherent relations between the crystal structure and the diffraction pattern can be solved by analyzing the diffraction peak 
RASĀYAN J. Chem.

Vol. 10 | No. 2 |665-672 | April - June | 2017

characteristics $^{20}$.X-Ray Diffraction spectra of the samples were taken using XPERT-PRO Diffractometer. $\mathrm{X}$-Ray scattering has been a unique and standard characterizing tool to investigate the structural properties of materials. In these studies one basically monitors either the intensity of elastically scattered .X-Ray photons as a function of the scattering angle in $\mathrm{XRD}^{21,22}$. The XRD characterizations of PURE PAN and $\mathrm{NaF}$ with different ratios are given in Fig.-2.

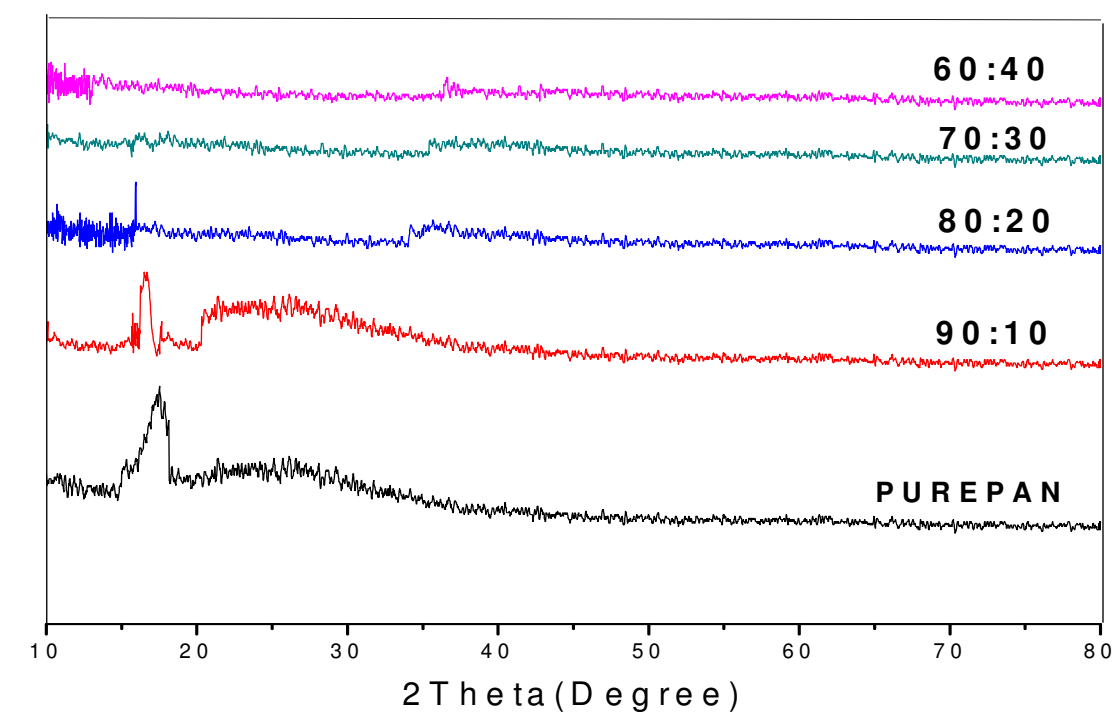

Fig.-2: XRD spectra of Pure PAN and different wt \% of PAN: NaF complexed films.

From the Fig.-2 reveals that the XRD pattern of Pure PAN exhibits well defined peaks are observed NaF which are indicates the crystalline nature of salt and also a broad peak is observed for Pure PAN corresponds to crystalline orthorhombic PAN (110) which is cantered at around $17.50^{\circ}$ and broad peak corresponds to amorphous content lies in between $10-30^{\circ}$ which corresponds to amorphous content indicating its semi crystalline nature..$^{23,24}$ The characteristic diffraction peaks of PAN-NaF at an angle $17.50^{\circ}$ and $16.07^{\circ}$ are reduced upon the addition of the plasticizers and $\mathrm{NaF}$ salt. The diffractograms in Fig.-2 reveals that the amorphous nature is predominant in the complex which is due to the addition of plasticizers. The diffraction pattern of PAN-NaF shows intense peak at an angles at $2 \theta=17.50^{\circ}, 16.68^{\circ}$ and $16.07^{0}$, which reveals the crystalline nature of the ionic salt ${ }^{25}$. The NaF salt content of $30 \mathrm{wt} \%$ peak disappeared in the complexes, which indicates the complete dissolution of the salt in the polymer matrix, PAN base NaF salt complex shows the amorphous state. A fully amorphous structure produces a greater polymer flow and ionic diffusivity. Hodge et al. ${ }^{26}$ established a correlation between the intensity of the peak and degree of crystallinity. From these results the XRD studies confirmed that there exist a complexation between the polymer and salt.

\section{AC Conductivity of PAN+ Sodium Fluoride (NaF)}

The A.C conductivity studies have been measured at room temperature range $303 \mathrm{~K}$ by using HIOKO 3532-50 LCR HITESTER over a frequency range $42 \mathrm{~Hz}$ to $5 \mathrm{MHz}$, The Gel polymer Electrolyte's bulk resistance was measured by using AC conductivity at room temperature (303K). It can be revealed that conduction mechanism to be the Arrhenius-type thermally activated process. This mechanism can be calculated by Impedance spectroscopy. The conductivity mechanism greatly depends upon the ions mobility concentration ${ }^{27}$. Conductivities of the film at room temperatures were calculated using the formula $\sigma=\mathrm{L} / \mathrm{Rb} \mathrm{A}$, where $\mathrm{L}$ is the thickness of the sample and $\mathrm{A}$ is the electrode area. The bulk resistance $(\mathrm{Rb})$ of polymer electrolyte for all samples was calculated from the interception of the semi-circular arc on the real impedance (Z') axis. With the increase of salt concentration the bulk resistance decreases due 
to the increase in the mobile charge carriers. Fig. -4 shows the variation in the AC conductivity $\left(\sigma_{\mathrm{AC}}\right)$ with the $\mathrm{NaF}$ concentration, measured at different frequencies.

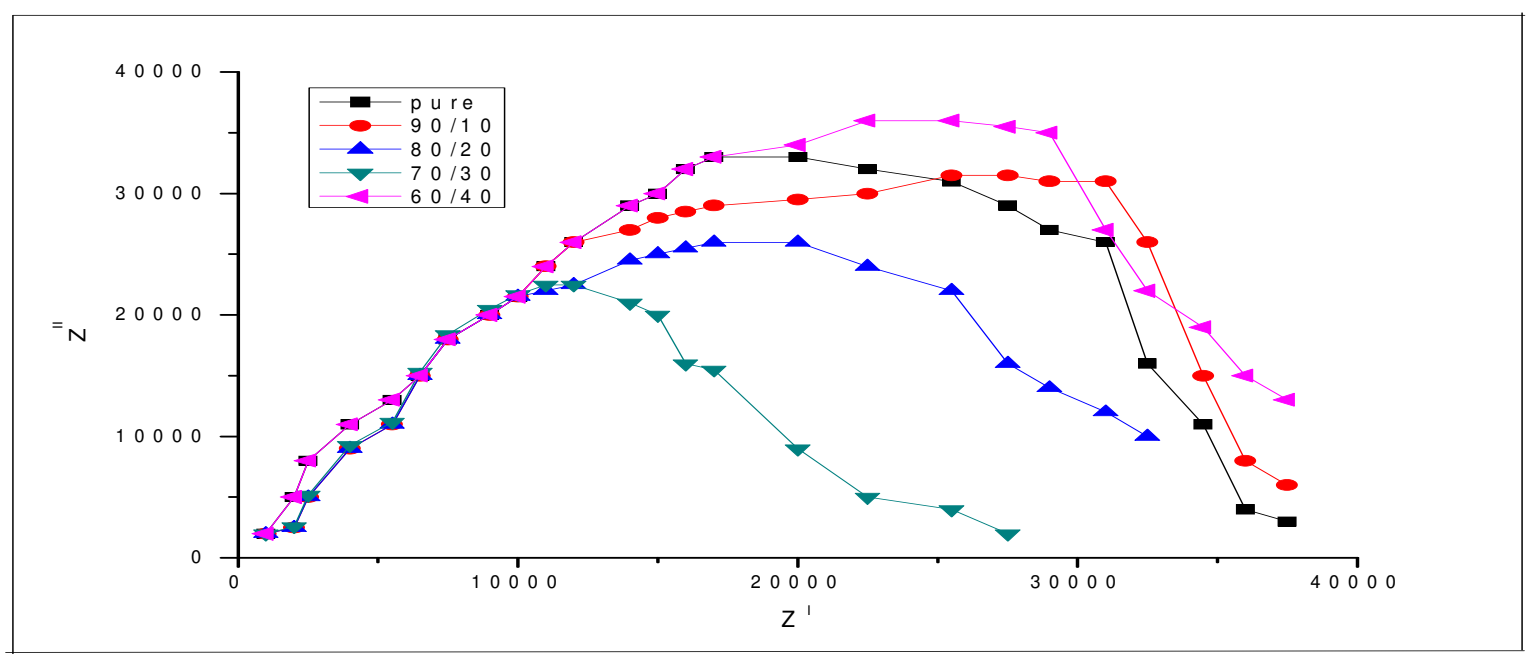

Fig.-3: Impedance plot for the conductivity of polymer electrolyte PAN: NaF at Room temperature

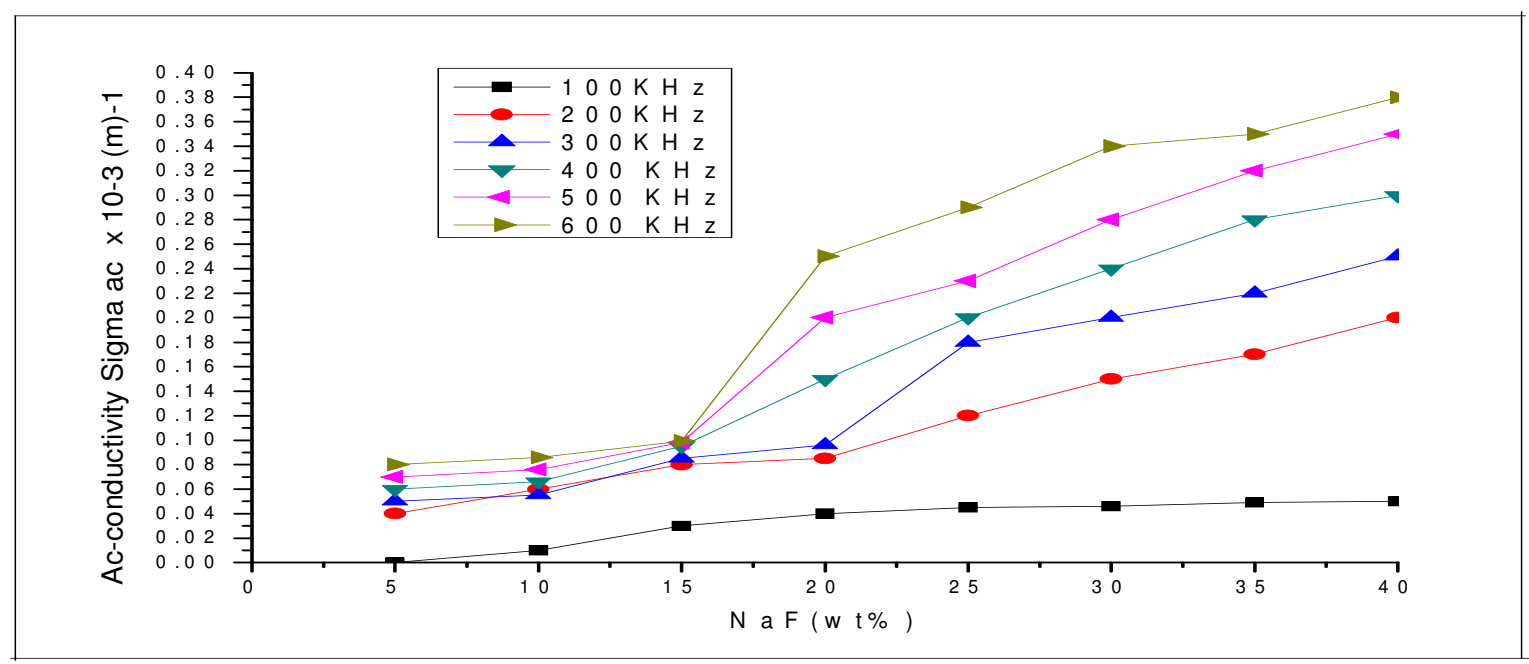

Fig.-4: AC conductivity Studies with diff wt $\% \mathrm{NaF}$ concentration.

The AC Conductivity is nearly constant up to $10 \mathrm{wt} \%$, after that, it increases rapidly with increasing NaF salt concentration. The value of about $10 \mathrm{wt} \%$ dopant content can be considered a critical one and called a percolation threshold for the thin films composites ${ }^{28,29}$.It is a general thought that the AC conductivity is related to frequency as reported in the empirical Jonscher universal law model which is given by the equation $\left(\sigma_{\mathrm{AC}}(f)=\sigma_{\mathrm{DC}}+\mathrm{B} f^{m}\right)$. Where $\mathrm{B}$ and $\mathrm{m}$ are coefficients, $\mathrm{f}$ is the frequency of the applied field $(\mathrm{Hz})$, $\sigma_{\mathrm{DC}}$ is the DC conductivity of the material, and $\sigma_{\mathrm{AC}}$ is the AC conductivity in $(\Omega \mathrm{m})^{-1}$. At higher frequencies, the conductivity increases as a power of frequency with exponent $0<\mathrm{m}<1$.In this case, $\mathrm{B}$ and $\mathrm{m}$ are temperature dependents. The ionic conductivity increases with increasing NaF content from 10$40 \mathrm{wt} \%$. The enhancement in conductivity is not only due to the increment of salt, but also due to Ethylene Carbonate (EC).This allows greater dissolution of the electrolyte salt resulting in increased number of charge carriers hence conductivity ${ }^{30}$.

Initially by adding the salt concentration the conductivity also increasing, because of the charge carriers increasing but at high concentration the conductivity of the compositions decreases due to an effect of ion segregations and higher ion pairs which decreases the mobility and charge carriers. The data reveals that 
the change occurs in conductivity values due to increasing of mobility in charge carriers with respect of salts ratios. In general as the conductivity values for 70PAN:30NaF increases the sharp peaks of the salt crystallinity decreases. The crystallinity in the salt the moment of ions obstructs by blocking its path, but there is an increasing of amorphous region due to its free volume this is due to the motion of an ionic charge, migration of ions through the amorphous region. Fig.-5 shows the AC conductivity studies depends upon temperature and $\mathrm{NaF}$ concentration. The AC conductivity increases with both temperature and dopant content. Using Arrhenius type equation, the activation energy (Ea) of the thermally conduction process can be estimated from the linear fit of the slopes in Fig.-5. Table-1 includes values of Ea obtained from the variation in AC conductivity with frequency measured in temperature range between $30-60^{\circ} \mathrm{C}$.

Table-1: The Activation Energy values\& Mobility for all samples at ( $\mathrm{f}=600 \mathrm{KHz})$.

\begin{tabular}{l|l|l}
\hline Polymer Electrolyte & Activation Energy $\left(\mathrm{E}_{\mathrm{a}}\right)(\mathrm{eV})$ & Mobility $(\mu)$ in $\left(\mathrm{m}^{2} / \mathrm{Vs}\right)$ \\
\hline 90PAN:10NaF & 0.47 & $1.24 \times 10^{-4} \mathrm{~m}^{2} / \mathrm{Vs}$ \\
\hline 80PAN:20NaF & 0.32 & $1.86 \times 10^{-4} \mathrm{~m}^{2} / \mathrm{Vs}$ \\
\hline $70 \mathrm{PAN}: 30 \mathrm{NaF}$ & 0.25 & $2.35 \times 10^{-4} \mathrm{~m}^{2} / \mathrm{Vs}$ \\
\hline $60 \mathrm{PAN}: 40 \mathrm{NaF}$ & 0.28 & $3.24 \times 10^{-4} \mathrm{~m}^{2} / \mathrm{Vs}$ \\
\hline
\end{tabular}

It can be seen that Activation Energy values decreases with increasing $\mathrm{NaF}$ content from $0.47 \mathrm{eV}$ for 90PAN: $10 \mathrm{NaF}$ to $0.28 \mathrm{eV}$ for the $60 \mathrm{PAN}: 40 \mathrm{NaF}$ wt $\%$ doped composite. This observed decrease in Activation Energy value implies that the energy of the prepared PAN: NaF thin films becomes narrower due to the creation of localized energy states by heating, which enhances the ion mobility and ability of the electrons to tunnel easily from the valence band to conduction energy band.

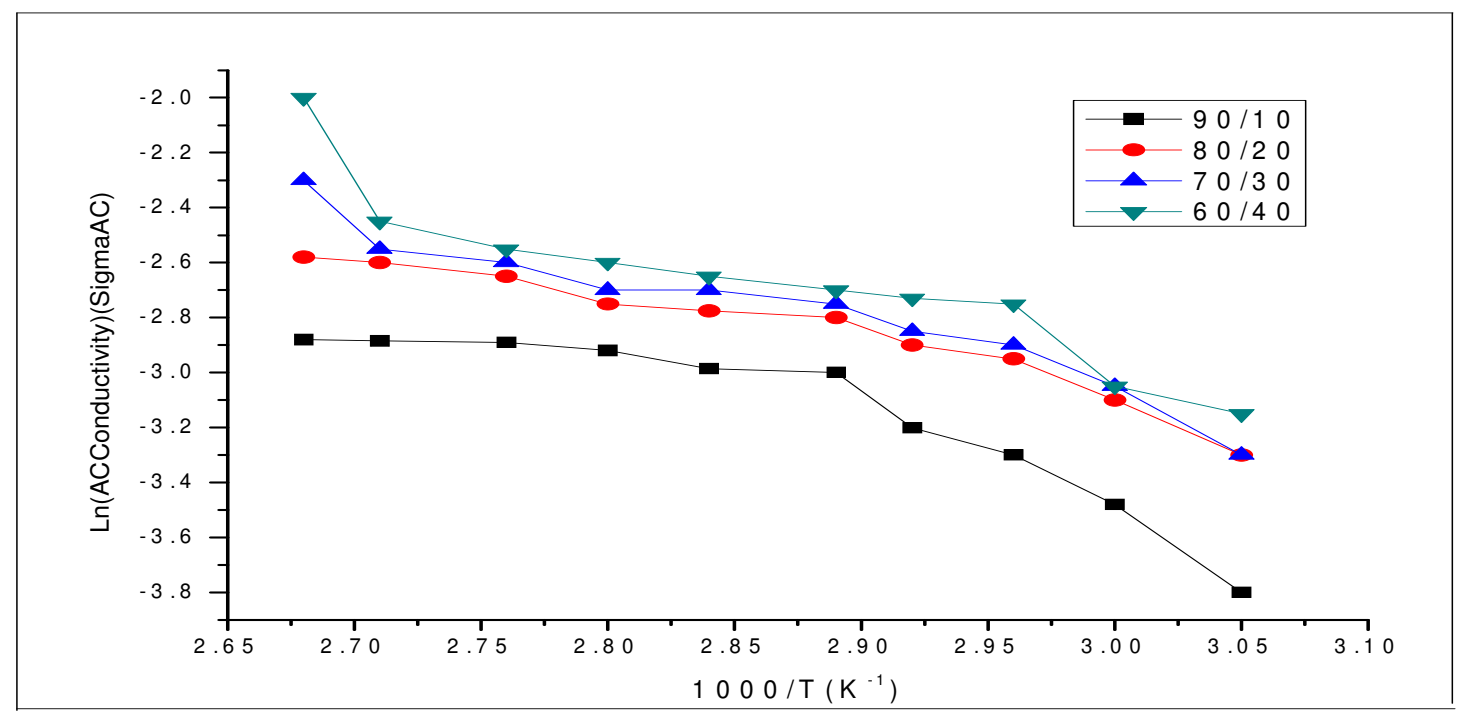

Fig.-5: Ln(AC Conductivity) Vs 1000/T for PAN: NaF composites at frequency $600 \mathrm{kHz}$.

These events increase the amorphous region in the polymer electrolyte and produce more active segmental motion, which stimulates the hopping mechanism and thus the conductivity becomes higher. This paper reports that the conductivity increases and Activation Energy decreases with respect of increasing $\mathrm{NaF}$ ratio. The temperature can be dominated by the mobility in the localized states bridged by the doped $\mathrm{NaF}$ molecules in the amorphous regions existing in the solid polymer electrolyte. Due to $\mathrm{NaF}$ concentration range, there is no optimum values observed under measuring conditions of applied field frequency, temperature, and $\mathrm{NaF}$ dopant content.

$$
\sigma_{\mathrm{AC}}=\sigma_{0} \exp \left[-\mathrm{E}_{\mathrm{a}} / \mathrm{K}_{\mathrm{B}} \mathrm{T}\right]
$$




\section{DSC Characteristics}

The differential scanning calorimetery (DSC) curves of PAN: NaF films are given in Fig.-6.From These Studies the glass transition temperature $\left(\mathrm{T}_{\mathrm{g}}\right)$ observed for PAN $107^{\circ} \mathrm{C}$ and the melting temperature $\left(\mathrm{T}_{\mathrm{m}}\right)$ observed $317^{0} \mathrm{C}^{31}$.

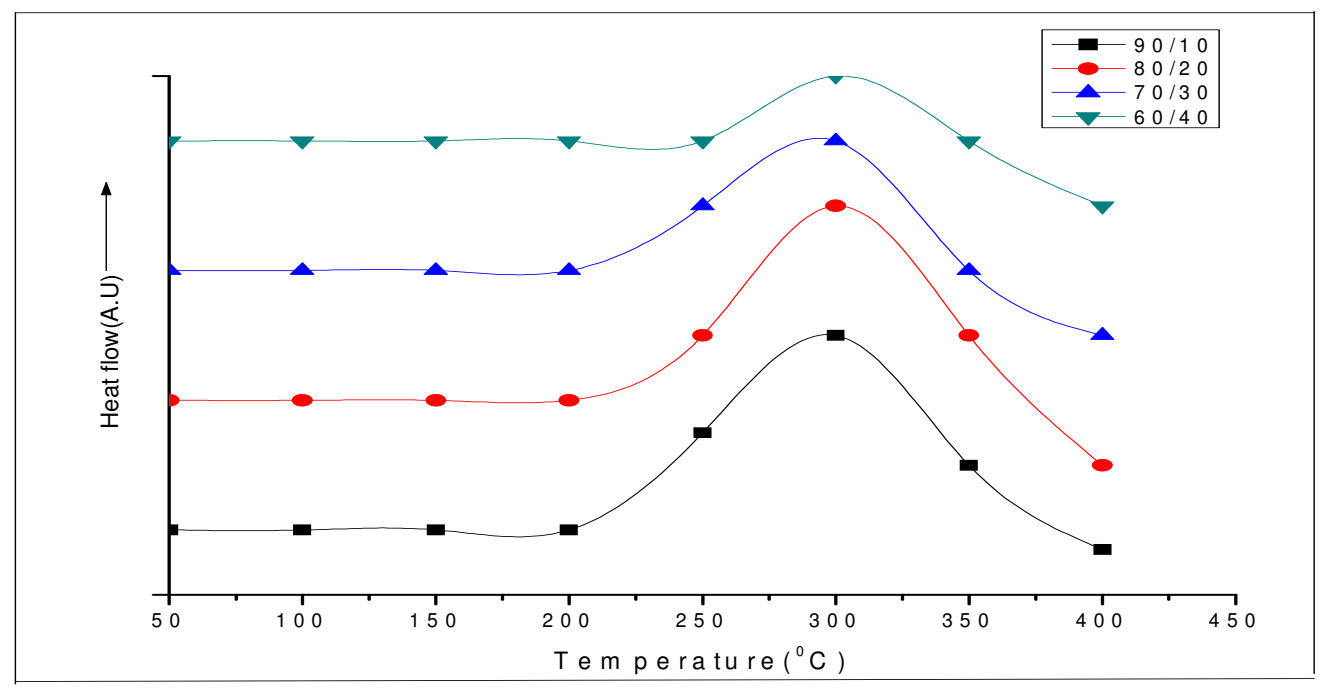

Fig.-6: DSC Studies for PAN: $\mathrm{NaF}$ complexed films at $40-400^{\circ} \mathrm{C}$

The films were subjected to Differential Scanning Calorimetric studies using Mettler-Toledo DSC 822e with a heating rate of $10^{\circ} \mathrm{C} / \mathrm{min}$. This technique is used to determine thermal properties of a polymer electrolyte system of a temperature range $10-400^{\circ} \mathrm{C}$.Endothermic and exothermic peaks are observed for glass transition temperature $\left(\mathrm{T}_{\mathrm{g}}\right)$ and melting temperature $\left(\mathrm{T}_{\mathrm{m}}\right)$. The microstructure and morphology of the system is accountable for the important parameters of polymer electrolyte membrane such as the glass temperature $\left(\mathrm{T}_{\mathrm{g}}\right)$, melting temperature $(\mathrm{Tm})$ and thermal stability. These parameters will affect the overall separator properties of the electrolyte material when operating in a battery ${ }^{32}$. The increase of NaF salt concentration into the host polymer (PAN) decreases the $\left(\mathrm{T}_{\mathrm{g}}\right)$ of the polymer. The decrease in $\mathrm{Tg}$ can be due to the plasticization effect of the gel polymer electrolyte with the addition of salt. The plasticization effect is related to a decreasing of the dipole-dipole interactions between the PAN chains due to the presence of the salt. In other words, the lowering of Tg of PAN is related to the lowering of degree of crystallinity. The lowering of $\mathrm{T}_{\mathrm{g}}$ is expected to make the ions move easily in the prepared polymer electrolyte systems. Similar results have been reported by Hiran Kumar et al. for the PVA: CH3COONH4 polymer electrolytesystem ${ }^{33}$. The low glass transition temperature has been found for $20 \mathrm{wt} \%$ of $\mathrm{NaF}$ doped PAN. The calculated $\mathrm{T}_{\mathrm{g}}$ values are listed in Table-2.These results were good agreement with conductivity values and XRD results.

Table-2: Glass Transition (Tg) values of PAN: NaF Complexed Gel polymer electrolyte films.

\begin{tabular}{c|c|c}
\hline S.No. & Sample & $\mathrm{T}_{\mathrm{g}}\left({ }^{0} \mathrm{C}\right)$ \\
\hline 1 & 100PAN:0NaF & 107 \\
\hline 2 & 90PAN:10NaF & 97.8 \\
\hline 3 & 80PAN:20NaF & 88.26 \\
\hline 4 & 70PAN:30NaF & 83.5 \\
\hline 5 & 60PAN:40NaF & 72.8 \\
\hline
\end{tabular}

For potential applications, the Polymer Gel Electrolytes must have high ionic conductivity, high transport number and wide electrochemical stability, thermal stability to guarantee an acceptable performance 
when it is operated at elevated Temparatures ${ }^{34}$. when plasticizer (EC) are added to PAN $\left(\mathrm{T}_{\mathrm{m}}\right)$ decreases from $317-294^{\circ} \mathrm{C}$ and $\left(\mathrm{T}_{\mathrm{g}}\right)$ decreases from $107-72^{\circ} \mathrm{C}$. When salt is added to PAN $\left(\mathrm{T}_{\mathrm{g}}\right)$ increases from $72-$ $98^{\circ} \mathrm{C}$ and $\left(\mathrm{T}_{\mathrm{m}}\right)$ increases from $294-312^{\circ} \mathrm{C}$. The interaction occurs between PAN and NaF salt due to enhance the concentration of salt from $10-40 \mathrm{wt} \%$. The $\left(\mathrm{T}_{\mathrm{g}}\right)$ and $\left(\mathrm{T}_{\mathrm{m}}\right)$ values were decreased due to increase in the plasticizers.

\section{CONCLUSION}

A Gel polymer electrolyte composite has been developed by blending varying concentration of NaF with pure PAN using solution casting method .These films were characterized by techniques such as XRD, AC Conductivity and DSC. The DSC measurements showed a decrease in the degree of crystallinity and increase of amorphous regions with enhancing concentration of salt. The sample containing 70PAN:30NaF exhibited the maximum conductivity of $1.82 \times 10^{-4} \mathrm{~S} \mathrm{~cm}^{-1}$ at room temperature (303K) and $2.96 \times 10^{-3} \mathrm{~S} \mathrm{~cm}^{-1}$ at $373 \mathrm{~K}$ respectively.

\section{ACKNOWLEDGEMENT}

The authors thank Er.Koneru Satyanarayana, President, Principal of KLEF and Dr. D. Hema Chandra Sagar Chairman and Dr.D. Prema Chandra SagarVice-Chairman.and Dr. Palla Rajeswar Reddy Chairman of Anurag Institutions for their support and encouragement.

\section{REFERENCES}

1. G. Sunita Sundari, K. Vijay Kumar.K. Veera Bhadra Reddy and M.C. Rao Rasayan J. Chem, 10(1), 279(2017).

2. M. Jaipal Reddy, J. Siva Kumar, U. V. Subba Rao and P. P. Chu, Solid State Ionics, 177, 253 (2006) .

3. K. Naresh Kumar, T. Sreekanth, M. Jaipal Reddy and U.V. Subba Rao, J. Power Sources, 101, 130 (2001).

4. Chithra M. Mathew, K. Kesavan, and S. Rajendran, Hindawi Publishing Corporation International Journal of Electrochemistry, Article ID 494308, 7(2015)

5. J. Ramesh Babu, K.Vijaya Kumar, International Journal of ChemTech Research, 7(1), 171(2014).

6. I. Blaszczyk-Lezak, V. Desmaret, C. Mijangos, eXPRESS Polymer Letters, 10(3), 259(2016)

7. S. Rajendran, S. Ravi Shanker Babu, P. Siva Kumar, J. of Memb. Sci., 67, 315 (2008).

8. D. Ravindran, T. Sornakumar, D.S Pritviraja Durai and V.Varatharajan, International Journal of ChemTech Research, 7(3), 1323(2014).

9. S. Rajendran, T. Mahalingam, R. Kannan, Solid State Ionics, 130, 143(2000).

10. M. Alamgir, K.M. Abraham, Journal of Power Sources, 54, 40 (1995).

11. K. V. Kumar, G. Sunitha Sundari, M. Chandra Sekhar, M. Ashok. International Journal of Chem Tech Research,3(3), 1203(2011).

12. S. Slane, M. Salomon, Journal of Power Sources, 55, 7(1995).

13. H. Yoon, W. Chung, Jo aN., Electrochemica Acta, 50, 289(2004).

14. Z. Wang, B. Huang, H. Huang, L. Chen, R. Xue, F. Wang, Solid State Ionics, 85, 143(1996).

15. Maragani Narasimha Rao, N. Krishna Jyothi and K.Vijaya Kumar, Int.J.Chem.Sci., 14(2), 789(2016)

16. B. Huang, Z. Wang, L. Chen, R. Xue, F. Wang, Solid State Ionics, 91, 279(1996).

17. G. Girish Kumar, S. Sampath, Polymer, 45, 2889(2004).

18. Maragani Narasimha Rao , N.Krishna jyothi,K.Vijayakumar, International Journal of ChemTech Research, 9(5), 432(2016).

19. D. Ravindran, T. Sornakumar, D.S Pritviraja Durai and V.Varatharajan, International Journal of ChemTech Research, 7(3), 1323 (2015).

20. M. M. Woolfran, An Introduction to X Ray Cambridge: Cambridge University Press, 1997 Crystallography, J. V. Gilfrich et al.( Eds.), Vol. 39 Advances in X-Ray Analysis, New York

21. J. Gurusiddappa, W. Madhuri R. Padma Suvarna, K. Priya Dasan, International Journal of Innovative Research in Science, Engineering and Technology, 4(11), 11447 (2015).

22. L. V .Azaroff, Mc Graw hill, 1968, Beltin EP. Plenum Press, 1978. 
RASĀYAN J. Chem.

Vol. 10 | No. 2 |665 - 672 | April - June | 2017

23. J. C. Lasseques, in P. Colomban (Ed.), Proton Conductors: Cambridge university press, Cambridge, 1992

24. F. Billmeyer, Jr., Text book of Polymer Science, (Wiley Singapore), 1984.

25. M. A. Ratner, D. F. Shriver, Chemical reviews, 88(1), 09(1988).

26. R. M. Hodge, G. H. Edward, G. P. Simon, Polymer, 37; 1371-1376, 1996.

27. R.F Bhajantri, V. Ravichandary, A. Harsha Vincent Crasta, Suresh P. Nayak, Bojapoojary, Polymer, 47, 3591(2006).

28. D. Stauffer, Introduction to percolation theory. London: Taylor and Francis, 1985.

29. V. I. Roldughin and V. Vysotskii. Review. Prog Org Coating., 39, 81(2000).

30. A.K. Jonscher. Chelsea Dielectric Press, 1983.

31. N. Krishna Jyothi, K.Vijaya Kumar, P.Narayana Murthy, Int.J.Chem.Tech.Res.,69(13),5214 (2014).

32. S. K. Sidhu, S. S. Sekhon, S. A. Hashmi and S. Chandra, Eur.Polym.J., 29, 779 (1993).

33. D .Saikia, Y.W Cheng-Yang, Chen, Y.T.Y.K .Li, S.I. Lin, Desalination 234, 24 (2008).

34. S. Selvasekharapandian, G. Hiran Kumar J. Kuwamura, N. Kuwata, T. Attori, Mater. Lett, 59, 2741(2005).

35. N. K. Jyothi, K. Vijaya Kumar, G. S. Sundari and P. N. Murthy, Indian J. Phys, 90(3), 289(2016).

RJC-1697/2017] 